\title{
A New Model to Determine the Personal Reference Interval of Tests in Laboratory Medicine: A Preliminary Study
}

\author{
Abdurrahman Coskun 1,2, Mustafa serteser1,2, Coskun Cavusoglu1, Meltem Kilercik1,2, \\ Ibrahim Unsal 1 \\ 1Acıbadem Labmed Clinical Laboratories, 2Acıbadem Mehmet Ali Aydınlar University \\ School of Medicine, Department of Medical Biochemistry
}

Corresponding Author: Abdurrahman Coskun, MD, Acibadem Mehmet Ali Aydinlar University School of Medicine, Department of Medical Biochemistry, Istanbul, Turkey Telephone: +905327446683

Fax: +902165765120

Coskun2002@gmail.com

"The authors have withdrawn this manuscript because they discovered errors in the equations that no longer support the findings given in the paper. Therefore, the authors do not wish this work to be cited as reference for the project. If you have any questions, please contact the corresponding author." 